\title{
Effects of rock dusting in preventing and reducing intensity of coal mine explosions
}

\author{
Yi Luo ${ }^{1} \cdot$ Deming Wang ${ }^{2} \cdot$ Jianwei Cheng ${ }^{2}$
}

Received: 13 January 2017/Revised: 15 March 2017/Accepted: 4 May 2017 / Published online: 1 June 2017

(C) The Author(s) 2017. This article is an open access publication

\begin{abstract}
As an explosion control measure, rock dusting has been used in underground coal mines in many major coal producing countries with different standards. The effectiveness of the rock dust in reducing explosion intensity has been proven by historic events and laboratory experiments. The main functions of rock dust in controlling mine explosions (i.e., isolator, physical heat sink and chemical energy absorber) have been quantitatively studied and results are presented in this paper.
\end{abstract}

Keywords Coal mine explosions · Rock dusting · Regulatory standards · Isolator · Heat sink · Energy absorber

\section{Introduction}

Explosions are the most feared hazards in underground mines. A coal mine explosion generally starts with the ignition of methane first with the possibility for the coal dust to participate in and to intensify the explosion. Mining coal generates $40 \mathrm{~g}$, on average, of float coal dust per ton of coal mined. Most of this float coal dust is deposited at or near the working sections. The possibility of methane ignition is also high at the working faces due to methane liberated from newly exposed coal face and possible frictional sparks generated in mining process. The effective control of coal dust on the working section is critical to prevent small methane ignitions at or near the working face from transitioning to a large coal dust explosion. Methane explosion can ignite the suspended coal dust, intensify the explosion event and produce more devastating consequences. Rock dusting has been used as a primary explosion prevention and intensity reduction measure in many major coal producing countries. Even though with different

Yi Luo

yi.luo@mail.wvu.edu

1 Department of Mining Engineering, West Virginia University, Morgantown, WV, USA

2 College of Safety Engineering, China University of Mining Technology, Xuzhou, Jiangsu, China standards, rock dusting is mandated in underground coal mines in the USA, Australia, South Africa, India, Russia, Germany, Poland,... Apparently, the frequency and severity of coal mine explosions are much smaller in these countries after this mine safety measure was in place than those in countries without mandating the rock dusting measure.

This paper briefly reviews the different rock dusting standards in the mine safety regulations established by the major coal producing countries. It shows the difference in explosion intensities between the methane only explosions and methane-coal-dust explosions. The evidences of applying rock dusting to the control of coal mine explosions are also shown. The main part of the paper is placed on gaining a basic qualitative and quantitative understanding about the mechanism of rock dusting in preventing and controlling coal mine explosions. With a better understanding, the strategy and effectiveness of using rock dusting as an important safety measure in underground coal mines can be improved.

\section{Histories and regulatory standards for rock dusting}

Rock dusting has been widely used in major coal producing countries. However, the quality and quantity standards for the rock dust vary to some degree. The bases for the 
variations could be related to the coal dust size, methane concentration in mine air, rank of coal, etc.

\subsection{Rock dusting standards}

Based on the US MSHA (Mine Safety and Health Administration) definition, the rock dust used in underground coal mine is pulverized and light colored limestone, dolomite, gypsum, anhydrite, shale, adobe, or other inert material. All the particles should be smaller than $841 \mu \mathrm{m}$ with $70 \%$ or more by weight being smaller than $74 \mu \mathrm{m}$ (MSHA 2014). Generally speaking, using such rock dust can greatly remove the amount of heat generated in an explosion event. Thus, the fire flame could be eliminated and the propagation of explosion within the underground ventilation system is prevented.

Due to such thermal inhibitive ability, applying rock dust (or rock dusting) to prevent or mitigate mine explosions is wildly used in US coal mines nowadays. Mine operators routinely cover the floor, rib and roof areas of mine entries with a generous application of inert rock dust (Man and Teacoach 2009).

It is generally agreed that the effectiveness of rock dust lies in its ability to be simultaneously dispersed with coal dust, and, by serving as a heat sink, thus prevent flame propagation. The regulatory requirements on rock dust are various, some are more and some less stringent among the countries (Cashdollar et al. 2010):

After the deadly Farmington mine explosion in US in 1968, the new Federal Coal Mine Health and Safety Act of 1969 mandated the use of rock dusting to prevent mine explosion. This mine safety law made significant improvement in mine safety and health in US underground coal mines, particularly in reducing coal mine explosions. Figure 1 shows the number of fatalities in each of the coal mine explosion disasters (defined as accident with five or more fatalities) and the cumulative mine explosion fatalities since 1900. Apparently, the frequency (measured by the density of the data points) and severity (the deaths per accident) before and after Act 1969 are significantly different. In the 70 years prior to this Act, 403 mine explosion disasters occurred resulting in a total of 10204 fatalities, or 5.76 accidents per year and nearly 25 deaths per accident on average. In the 40 years after the Act, there were 16 explosion disasters resulting in 210 deaths, average 0.4 accidents per year and 13 deaths per accident. There was apparently declining trends both in frequency and severity in the decade after the pass of the Act.

Initially, the rock dusting standard in US coal mines was mandated that $65 \%$ incombustible content (IC) in non-return airways and $80 \%$ IC in return airways (Harris et al. 2010). When methane is present in any ventilating current, it requires adding an extra $1 \%$ of incombustible material

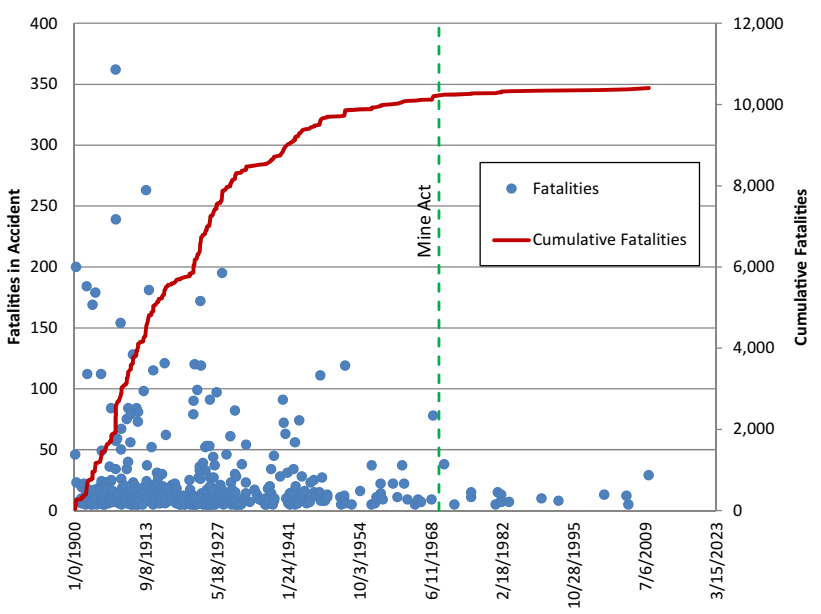

Fig. 1 US coal mine explosion disasters ( $>5$ fatalities/accident), 1910 - present

per $0.1 \%$ methane for air in intakes and adding $0.4 \%$ incombustible per $0.1 \%$ methane in the returns (Man and Teacoach 2009). To face the finer coal dust particle size produced by modern coal mining machines, MSHA increased the rock dusting standard on September 23, 2010. The new regulations require the total incombustible content (TIC) of combined coal dust, rock dust, and other dust to be at least $80 \%$ in underground bituminous coal mines with an additional requirement to raise the incombustible content by $0.4 \%$ for each $0.1 \%$ of methane present in the ventilation air.

Canadian coal mines follow different rock dusting criteria according to their locations. In Alberta and British Columbia, the minimum total incombustible content is $65 \%$ in intake airways while $75 \%$ is required in the province of Nova Scotia (Cain 2003). However, $80 \%$ TIC is needed for all return airways.

Regulations in Australia also vary. The required TIC ranges from $70 \%$ to $85 \%$ in intake airways and $80 \%-85 \%$ in returns in the state of Queensland. However, the maximum TIC is only $80 \%$ in intakes in New South Wales (Cashdollar et al. 2010).

Most East European countries, such as Czech Republic, Slovakia, Ukraine, etc., use the same standard requiring TIC to be $80 \%$ both in intakes and returns when the methane concentration is lower than $1 \%$ otherwise $85 \%$ is demanded. The requirements for TIC in Polish and Russian coal mines are less stringent. Differing with mine type, $60 \%$ and $70 \%$ are required in the intake and return airways for "non-gassy" mines and $75 \%$ and $80 \%$ are required for "gassy" mines, respectively.

South African mine researchers started the needs assessment of rock dusting in later 1980s. The last major coal mine explosion occurred in 1993 with 53 deaths. Currently, $80 \%$ TIC (both in intakes and returns) is 
required by the government regulations which were established as law in the year of 2002 (Cain 2003).

Although the criteria of TIC are mostly based on the methane concentration, some countries establish their criteria based on the volatile matter (VM) content of coal. In United Kingdom, TIC ranging from $50 \%$ to $75 \%$ is required as the VM content varies from $20 \%$ to $35 \%$. Japanese regulations specify a minimum TIC of $78 \%$ when the volatile matter content is over $35 \%$. More specific requirements are also needed depending on ash, moisture, the gassiness of the coal seam, and the fineness of the rock dust used.

\subsection{Considerations in rock dusts}

As shown early, the TIC in rock dust is the most important quality factor for preventing the propagation of mine explosion. Laboratory experiments show that different rock dusts (i.e., limestone, dolomite and magnesite) have similar inerting effectiveness for coal dust. However, tests with dolomite show that a decrease in rock dust particle size could significantly lower the amount required to inert (Amyotte et al. 1992). Limestone or other rock dusts could easily cohere to form a cake when wetted and then dried making dispersion more difficult in an event of a light blast of air. Hence, the effectiveness of the alternative inerting agents has been experimentally investigated in countries including Germany, US, South Africa, etc. Fly ash and calcium sulphate $\left(\mathrm{CaSO}_{4}\right)$ may be the good candidates but more testing works are required to prove this.

Rock dust bags are extensively used in some counties to create barriers for stopping explosion propagation. In order to make this explosion mitigation measure effective, the barriers should be properly placed and a certain minimum pressure is required to activate them. Various reports show more failure than successes in using this explosion mitigation measure (Zou and Panawalage 2001). Most failures are attributed to improper location, improper design, poor installation, and inadequate maintenance. If the explosion is too weak to disperse the selves-often as a result of placing the rock dust barriers closer than $60 \mathrm{~m}$ from the ignition point, a failure may occur. In addition, if the pressure front or the flame front moves too fast or is too short, the flame front could have easily passed the barrier locations before the dispersion of inert material is completed (Dixon et al. 1994).

The rock dust is considered as nuisance dust that should have no adverse effect to the health of the miners, especially to the workers performing the rock dusting operations. However, it should be noted that research on the effects of rock dust to miners' health is still limited. The most important factor to consider is the content of silica $\left(\mathrm{SiO}_{2}\right)$. Any extended accumulation of dust with high silica content in human lungs, together with the tissue reaction to its presence, is usually referred to as pneumoconiosis (Du Plessis 2014). Therefore, for miners' health, MSHA requires that the rock dust not contain more than $5 \%$ combustible matter or more than a total of $4 \%$ free and combined silica $\left(\mathrm{SiO}_{2}\right)$. However, further medical studies should be performed on silica and other mineral components in the rock dust to determine their effects to human health.

\section{Current Chinese coal mine explosion prevention measures and results}

Watering, water flushing, water mist spray and water barriers (Fig. 2) have been extensively used to prevent and reduce intensity of coal mine explosions in China. Coal mines in the eastern China, especially for the coal fields such as Zhaozhuang, Yanzhou, Huainan, Huaibei, etc., often apply the methods of watering and water flushing to clear float coal dusts in underground. The underground roadways with serious coal dust deposition problems are regularly washed with water. Since most of the Chinese coal mines are designed to use gravity drainage system and drainage ditch is built in each roadway, using water to wash the float coal dust generally will not create drainage problems. The period of washing is determined by the dust deposition density and the minimum dust concentration required by a coal dust explosion. The washing work should be done routinely every day especially in the sections less than $30 \mathrm{~m}$ from the dust sources. In addition, due to their shallow mining depths, high productions and water shortage problems, coal mines in the western China often spread rock dust to prevent coal dust explosion.

Chinese coal mines also spread the rock dust in the underground to cover the exposed coal. It is required that the incombustible content of combined coal and rock dusts

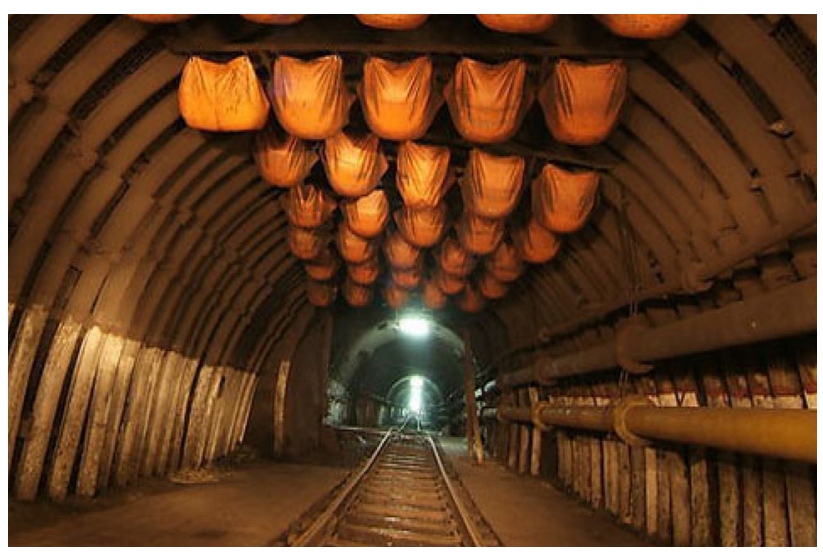

Fig. 2 Water barriers in Chinese underground coal mines 
must be at least $60 \%$ or $90 \%$ when the $\mathrm{CH}_{4}$ concentration is over $0.5 \%$. The quality of rock dust must meet the following quality requirements: (1) the combustible content $<5 \%$, (2) the content of free silica $\left(\mathrm{SiO}_{2}\right)<10 \%$, (3) free of any toxic or harmful mixture, such as phosphorus and arsenic. The rock dust, mainly limestone dust, should entirely pass through 50 mesh sieve $(<300 \mu \mathrm{m}$ in sizes), and $70 \%$ of it pass through 200 mesh sieve $(<75 \mu \mathrm{m}$ in sizes) (Safety SAOW 2006). The rock dusting requirements, established in 2006, have not been made into the mining law and only serve as the suggested mine safety measure.

In preventing underground explosion, China initially adopted the Polish measures to use the rock dust barriers. However, the "caking" problems of the rock dust limited its effectiveness in explosion control. Since 1980s, water barriers have been extensively used as an explosion mitigation measure in Chinese underground mines. The principles of water barrier are similar as rock dust barrier. In an explosion event, the precursor shock wave would overturn the water barriers or break the water bags to release the stored water into the air. The released water, if fully mixed with the flame front, can greatly reduce the explosion intensity by acting as heat sinker and flame retardant. The effects of water on preventing mine gas/dust explosion under specific experimental conditions are evident. However, when the water is poured from its containers in underground conditions, it is often poorly dispersed in space and can only suspend in air for a short duration. Therefore, the potential effectiveness of the water barriers in suppressing the explosion is greatly reduced. The water barriers' poor performances in preventing underground explosions have been evidenced by a number of serious mine explosion accidents in Chinese coal mines. Hence, the necessity and reliability of water barriers are now questioned by a number of Chinese mine safety experts and engineers.

\section{Mechanism of rock dusting in controlling coal mine explosions}

In order to effectively use the rock dust in controlling coal mine explosions, the mechanism for the applied rock dust to control explosion should be qualitatively identified and the effectiveness should be quantitatively evaluated. To control an on-going coal mine explosion, the first important step is to lower the air temperature as fast as possible for the purpose of lowering the explosion pressure. The second important step is to prevent coal dust from participating into explosion so that the total thermal energy produced and the intensity of an explosion can be controlled. Properly applied rock dust can achieve both the control steps.

\subsection{Main mechanisms}

In the underground coal mine settings, the essential conditions for coal dust to participate in an explosion are: (1) fine coal dust suspended in air with a minimum concentration of $100 \mathrm{~g} / \mathrm{m}^{3}$ for biyuminous coal and (2) sufficient ignition energy with a minimum temperature of $440{ }^{\circ} \mathrm{C}$ (Stephan). The first condition ensures sufficient reaction surface between the fine coal dust particles and oxygen in the air. The second condition provides sufficient thermal energy to ignite the coal dust and to sustain the chain explosion process. It should be noted that among the combustible contents in the coal (mainly the volatile matters and the fixed carbon), the volatile matters should be the first part and most likely the only part to be involved in the explosion process considering the short contact time between the passing hot air and the coal dust particles. However, the volatile matters have to be devolatilized, stimulated with sufficient thermal energy, into vapor before the start of dust explosion.

Proper rock dusting in underground coal mines can effectively eliminate the two conditions for coal dust to participate in explosion. The inert rock dust can function as isolator, physical heat sink and chemical energy absorber. The heavier rock dust applied over the lighter coal dust can serve as an isolator to prevent the coal dust underneath from becoming easily airborne. The isolator is most likely to function only when the explosion front is propagate at a relatively low velocity. Without suspending the deposited coal dust into the mine air, it is very unlikely for the lower explosive limit of coal dust to be reached.

In a methane explosion event, the explosion propagation can quickly reach supersonic and thus generates shock wave. The shock wave is well capable of suspending the settled coal and rock dusts into mine air. Under this condition, the suspended rock dust along with the unexploded coal dust can act as a physical heat sink to absorb the heat in the passing hot air for creating a temperature equilibrium between the dust and air. Based on the law of energy conservation, a simplified model can be derived for assessing the rock dust's heat sink effect. For example, a coal dust load is assumed to be $1.2 \mathrm{~kg}$ per meter length of a $2 \mathrm{~m} \times 6 \mathrm{~m}$ mine entry to create dust-air mixture at the minimum explosive concentration of $100 \mathrm{~g} / \mathrm{m}^{3}$ if fully suspended in the air. To demonstrate the heat sink effect of rock dusting, the entry is dusted with limestone powder at $0.00,2.23$ and $4.80 \mathrm{~kg}$ per meter of entry to create $0 \%$, $65 \%$ and $80 \%$ rock dust concentrations, respectively. In an explosion event, the passing hot air at $2000{ }^{\circ} \mathrm{C}$ suspends and fully mixes with the coal and rock dusts at a point. The airborne coal and rock dusts (originally at ambient temperature of $16{ }^{\circ} \mathrm{C}$ ) absorb the heat from the hot air and lower its temperature. 
Figure 3 shows the resulting air temperature profiles in the entry for the three simulated cases. Without rock dusting ( $0 \% \mathrm{RD})$ and assuming that the airborne coal dust will not explode due to insufficient concentration, the air temperature in the entry decreases slowly. The air temperature is reduced to about $440{ }^{\circ} \mathrm{C}$, the minimum ignition temperature for coal dust, at a distance of $31 \mathrm{~m}$ from the source. On the other hand, it takes about 14 and $8.5 \mathrm{~m}$ distances to lower the air temperature to $440{ }^{\circ} \mathrm{C}$ when $65 \%$ and $80 \%$ rock dusts are applied in the entry, respectively. The shorter distance for the mine air to remain above the minimum ignition temperature of coal dust, the less is the possibility for the coal dust to participate in mine explosion. Therefore, the heat sink effect of the proper rock dusting can greatly reduce the possibility of coal dust ignition in a mine explosion event.

The third function for the rock dust to control mine explosion is to chemically absorb the thermal energy in a calcination process. At temperature above $800{ }^{\circ} \mathrm{C}$, the main component of the rock dust, limestone $\left(\mathrm{CaCO}_{3}\right)$, can be converted into lime $(\mathrm{CaO})$ in an endothermic chemical reaction process as shown in Eq. (1). A complete chemical reaction of one $\mathrm{kg}$ of pure limestone dust absorbs about $1786 \mathrm{~kJ}$ heat (Zeman 2008). The thermal energy consumed in the limestone-to-lime chemical conversion process can reduce the chance and intensity of the methane and coal dust explosion.

$\mathrm{CaCO}_{3}+$ heat $=\mathrm{CaO}+\mathrm{CO}_{2}$

The combustion process of fine coal particles at high temperature involves two stages: the ignition and combustion of volatile maters (VM) first and then the fixed carbons (Prins et al. 1989). At $850{ }^{\circ} \mathrm{C}$, the ignition of the fixed carbon normally occurs more than $10 \mathrm{~s}$ after the ignition of VM. In a mine explosion event, the contact time between the coal dust particles and hot air in the chemical reaction zone is very

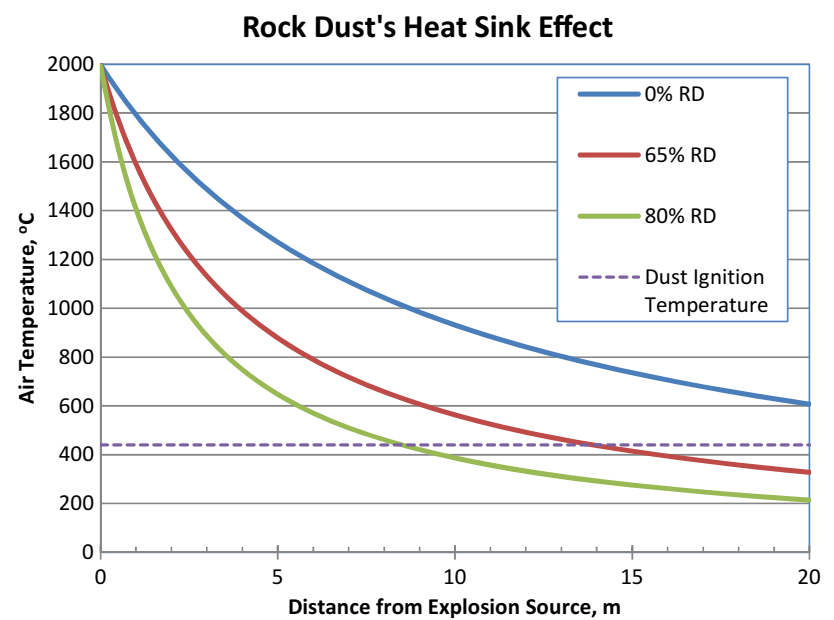

Fig. 3 Rock dust's heat sink effect for lowering the mine air temperature short. Therefore, it is most likely that only the VM of the coal or even only a portion of the VM can be vaporized and participated in mine explosion. This is the reason that anthracite (VM less than 10\%) dust is impossible to explode while the explosibility of the coal dust increases as the rank of the coal decreases (higher VM content). In an idealized condition where all and only the VM in the coal dust participates in explosion and the calcination process is complete, a balance in the thermal energies produced by coal dust explosion and consumed by the calcination process can be determined using the following equation.

$x=\frac{1786 \alpha}{(1-\alpha) \mathrm{Q}}$

In this equation, $x$ is the VM content, $\alpha$ is the rock dust concentration and $Q$ is the heating value of the coal. If $80 \%$ rock dust is applied and $Q=30,000 \mathrm{~kJ} / \mathrm{kg}$ for typical coal, the $\mathrm{VM}$ content required to reach an energy equilibrium is determined to be $23.8 \%$. In other words, if a coal contains less than $23.8 \% \mathrm{VM}$, the complete calcination process can absorb more heat than that the coal dust can generate in the explosion. Consequently the calcination process will consume thermal energy in the hot air and lowers its temperature. Even for the coals having higher VM contents, the energy consumed in the calcination process of the rock dust can still greatly reduce the net thermal energy added by coal dust to the explosion event.

\subsection{Anecdote evidences}

The anecdote evidence for rock dust to control coal dust explosion is shown in the demonstration tests conducted at the South Africa's CSIR (Council for Scientific and Industrial Research) Kloppersbos facility (Fig. 4). In the
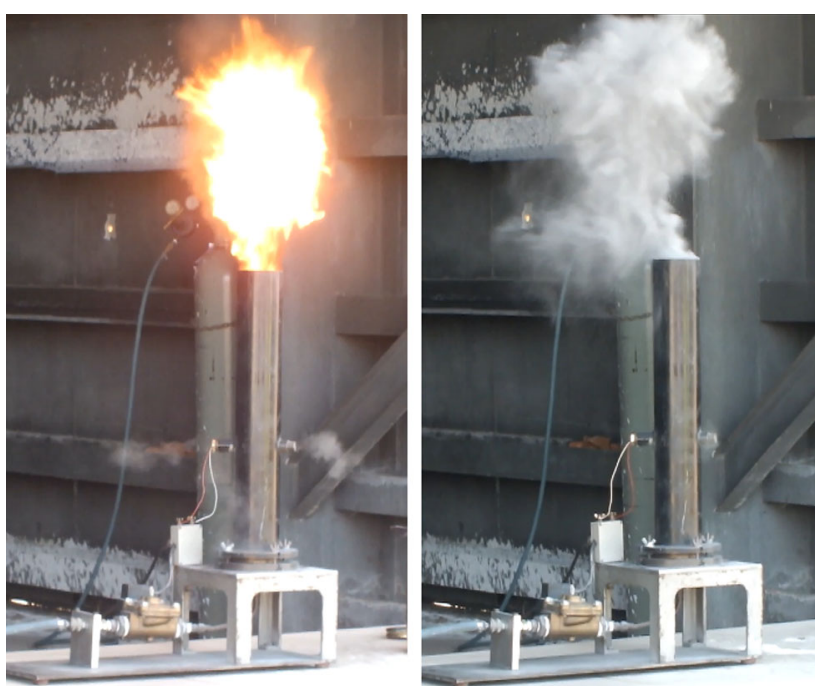

Fig. 4 Coal dust explosion tests of one teaspoon of coal dust without (left) and with (right) four spoon of rock dust (80\% rock dust) 
demonstrations, the explosion of one teaspoon of coal dust in a steel tube results in a large fire ball above the tube as shown in the left of figure and a loud noise. When one teaspoon of coal dust is mixed with 4 teaspoons of rock dust (80\% RD), the explosion only resulted in a quiet puff of white dust cloud above the mouth of the tube as shown in the figure on the right. It indicates that the rock dust has considerably reduced the total energy output from the dust explosion.

The recent two explosions in the US coal mines (Sago in 2006 and Upper Big Branch in 2010) show the importance of rock dusting in reducing the intensity of mine explosion. In the Sago mine explosion, the mine was properly rock dusted. The methane explosion was originated from a newly sealed mine area that completely destroyed the mine seals. The back calculated explosion pressures at the mine seals was about $641 \mathrm{kPa}$ (Gates et al. 2007). The immediate impact of the explosion caused one death to a mining crew of 13 located about $123 \mathrm{~m}$ from the destroyed mine seals (about $34.5 \mathrm{kPa}$ explosion pressure). The other 11 fatalities in this accident were caused by $\mathrm{CO}$ poisoning. Another crew of 13 miners located about $344 \mathrm{~m}$ away from the destroyed mine seals (about $14 \mathrm{kPa}$ explosion pressure) escaped from the accident unharmed. The sharp decrease of the explosion pressure within a short distance from the explosion source implies the effectiveness of rock dusting in reducing the explosion intensity.

On the other hand, the explosion in the Upper Big Branch mine almost instantly killed 29 miners located within a radius of more than $2500 \mathrm{~m}$ from the source of the explosion (Phillips 2012) indicating that the explosion pressure in this accident is significantly higher than that in Sago accident. Substandard rock dusting was common in this mine and the mine had been cited numerously for coal dust piles and insufficient rock dust by federal and state mine inspectors. The high intensity indicated heavy participation of coal dust in the explosion event.

\subsection{NIOSH explosion tests}

After the Sago Mine explosion, the US National Institute for Occupational Safety and Health (NIOSH) conducted a series of explosion tests in its Lake Lynn experimental mine (Zipf et al. 2013). In the explosion tests, natural gas was injected into an ignition zone (most time with a volume of $21.5 \mathrm{~m}^{3}$ and a few with larger volume). The natural gas is composed of $97 \%-98 \%$ methane, $1.5 \%$ ethane, and small percentages of other higher hydrocarbons. Most of the tests used a 9\% methane-air concentration in the ignition zone. A few of the tests were also conducted with 6\%-10\% methane-air concentrations. In six of the tests, shelves of pulverized bituminous coal dust $(7.3,14.5$ and $120 \mathrm{~kg}$, respectively) were located at a distance of 3-12 m away from the ignition zone as a means to increase the explosion overpressures. A number of important explosion parameters (i.e., pressure, temperature, time of flame front, etc.) were measured during the tests. The author reanalyzed some of the data. One of the findings of the data analysis is the nearly linear relationship between the maximum static explosion pressures and the total heating value possibly released in the explosion as shown in Fig. 5. The maximum static explosion pressures were measured at the location about $4 \mathrm{~m}$ away from the ignition zone. The total amount of methane and only the volatile matter (30\% VM for bituminous coal) of the coal dust are used to determine the total heating values. Figure 5 shows when only methane is involved in the explosion, the maximum explosion pressure at the experiment sitting reaches only about $234 \mathrm{kPa}$ (34 psi). However, as the coal dust is added in the explosion, the pressure increases considerably. In the last explosion test with $120 \mathrm{~kg}$ of coal dust being placed in the testing site, the maximum explosion pressure reached about $620 \mathrm{kPa}(90 \mathrm{psi})$. The good linear relationship also indicates that it is reasonable to assume only the VM content of the coal to participate in the mine explosion as previously shown in the quantification of the rock dust's chemical energy absorber function.

\section{Rock-dusting in underground coal mines and regulatory compliance}

Rock dusting is currently the primary means of defense against coal dust explosions in US underground mines mining bituminous coals. All areas of a coal mine that can be safely traveled must be adequately rock dusted within $12 \mathrm{~m}$ of all working faces. The chance of propagation and risk of widespread explosion disasters in bituminous coal

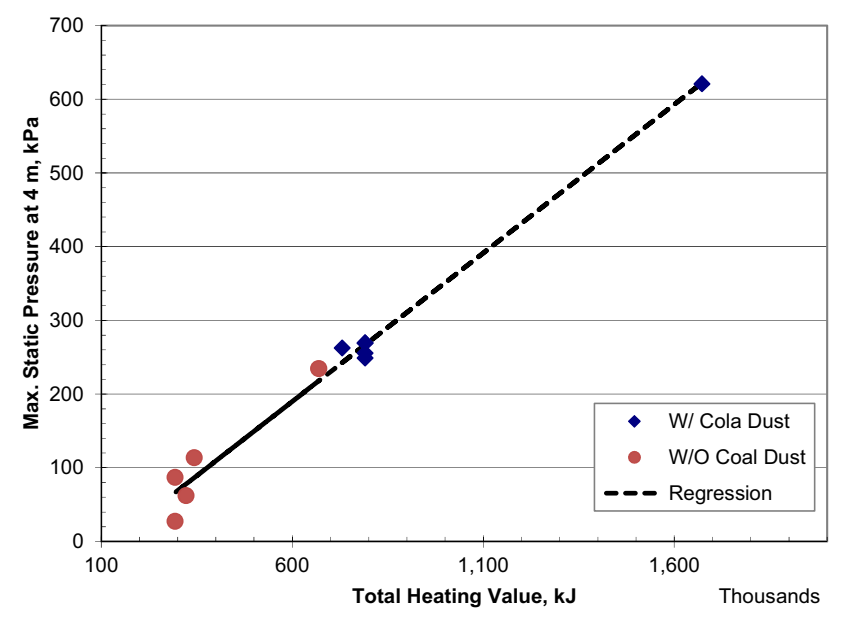

Fig. 5 Total heating value versus maximum explosion pressure (reanalyzed NIOSH test results) 


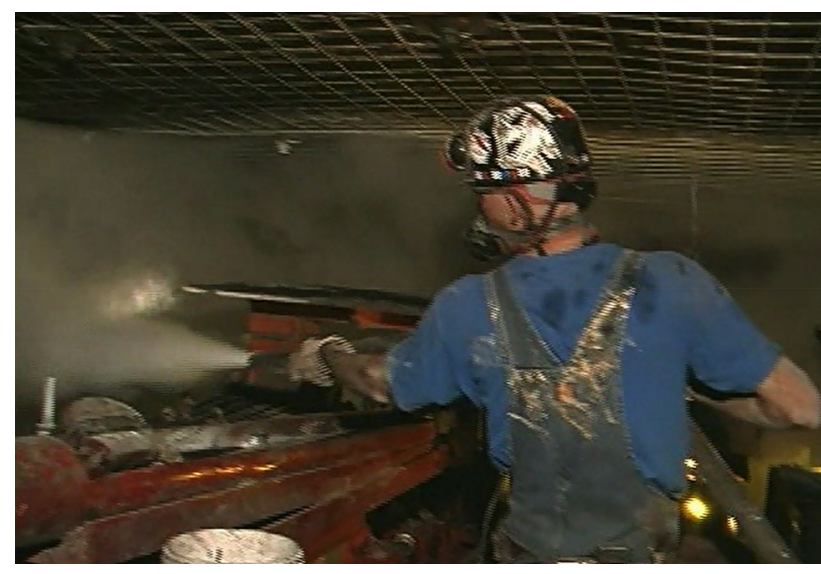

Fig. 6 Manual application of rock dust in a new face area

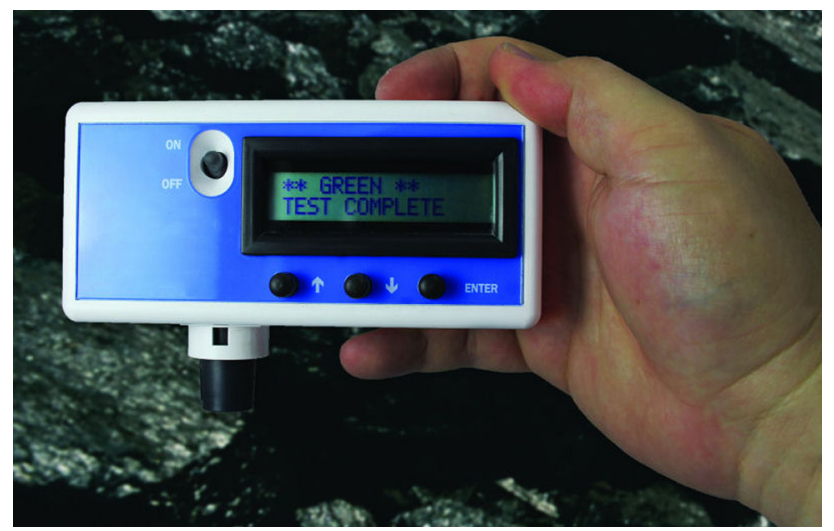

Fig. 7 NIOSH developed coal dust explosibility meter (CDEM)

mines can be nearly eliminated when rock dust is applied liberally and maintained properly. Figure 6 shows a manual rock dusting operation in a new coal working face. Various mechanized rock dusters are commercially available. The mine operators are responsible for maintaining the required minimum incombustible content in the mine.

The incombustible content of rock dust is evaluated during regular and spot inspections. This evaluation includes the collection and analysis of mine dust samples. To assess the compliance, mine dust samples are collected from various locations within the coal mine. The band or perimeter method is used to collect dust samples from the roof, ribs, and floor creating one "band" sample. This band sample includes $25 \mathrm{~mm}$ deep material from the floor. The collected sample is thoroughly mixed, coned, and quartered to take a portion for analysis. This sampling essentially assumes a homogeneous mixture of coal, rock, and other dust on all surfaces.

Traditionally, the collected samples are sent to the National Air and Dust Laboratory for moisture and low temperature ash analysis to determine the percent of incombustible content of the minus 20 mesh fraction. A new handheld device, the coal dust explosibility meter (CDEM) shown in Fig. 7, has been developed by the NIOSH. The CDEM can be used at the sampling sites to accurately determine the explosibility of rock and coal dust mixtures nearly in real time.

\section{Conclusions}

Rock dusting has been used in many major coal producing countries as the primary means of defense against coal dust explosions in underground coal mines. A proper rock dusting should maintain adequate incombustible content in the mine dust mixtures of float coal dust and rock dust. The rock dust applied can function as isolator, physical heat sink and chemical energy absorber that prevent the settled coal dust from participating into explosion and reduce the total thermal energy contained in the explosion event. Through such functions, the rock dust can either stop a coal mine explosion process or reduce its intensity.

Open Access This article is distributed under the terms of the Creative Commons Attribution 4.0 International License (http://crea tivecommons.org/licenses/by/4.0/), which permits unrestricted use, distribution, and reproduction in any medium, provided you give appropriate credit to the original author(s) and the source, provide a link to the Creative Commons license, and indicate if changes were made.

\section{References}

Amyotte PR, Mintz KJ, Pegg MJ (1992) Effectiveness of various rock dusts as agents of coal dust inerting. J Loss Prev Process Ind 5(3):196-199

Cain P (2003) The use of stone dust to control coal dust explosions: a review of international practice. Report to Natural Resources Canada, p 46

Cashdollar KL, Sapko MJ, Weiss ES, Harris ML, Man CK, Harteis SP, Green GM (2010) Recommendations for a new rock dusting standard to prevent coal dust explosions in intake airways. Centers for Disease Control and Prevention, NIOSH RI 9679, p 49

Dixon DW, Fidler WM, Ediz IG (1994) The preliminary analysis of the pressure wave transmission/reflection characteristics of explosion doors using one-imensional finite isentropic wave theory. In: Proceedings of the 9th Coal Congress of Turkey, Zonguldak, pp 319-330

Du Plessis J (2014) Ventilation and occupational environment engineering in mines. Mine Ventilaiton Scociety of South Africa, Johannesburg

Gates RA, Phillips RL, Urosek JE, Stephan CR, Stoltz RT, Swentosky DJ, Harris GW, O'Donnell JR, Dresch RA (2007) Report of Investigation Fatal Underground Coal Mine Explosion January 2, 2006 Sago Mine, MSHA, p 613

Harris ML, Weiss ES, Man CK, Harteis SP, Goodman GV, Sapko MJ (2010) Rock dusting considerations in underground coal mines. In: Proceedings of the 13th US/North American Mine Ventilation Symposium, Sudbury, Ontario, Canada, MIRARCO-Mining Innovation, pp 267-271 
Man CK, Teacoach KA (2009) How does limestone rock dust prevent coal dust explosions in coal mines? Min Eng 61(9):69

MSHA (2014) Rock dusting. arlweb.msha.gov/S\&HINFO/RockDust ing/RockDusting.asp

Phillips CA (2012) Report of Investigation into Mine Explosion at the Upper Big Branch Mine, WV Office of Miners' Health, Safety and Training, p 230

Prins W, Siemons R, Van Swaaij WPM (1989) Devolatilization and ignition of coal particles in a two-dimensional fluidized bed. Combust Flame 75:57-79

Safety SAOW (2006) Technical specifications of comprehensive dust control measures for underground coal mine (in Chinese)
Stephan CR. Coal dust explosion hazards, p 10. https://arlweb.msha. gov/S\&HINFO/TECHRPT/P\&T/COALDUST.pdf

Zeman F (2008) Effect of steam hydration on performance of lime sorbent for $\mathrm{CO}_{2}$ capture. Int J Greenh Gas Control 2(2):203-209

Zipf RK, Gamezob VN, Sapkoa MJ, Marchewkaa WP, Mohameda KM, Oranb ES, Kesslerb DA, Weissa ES, Addisa JD, Karnacka FA, Sellersa DD (2013) Methane-air detonation experiments at NIOSH Lake Lynn Laboratory. J Loss Prev Process Ind 26(2):295-301

Zou DH, Panawalage S (2001) Passive and triggered explosion barriers in underground coal mines-a literature review of recent research. Report to CANMET Natural Resources Canada, p 65 